\title{
Oral health seeking behaviors of adults in Nebbi District, Uganda: a community-based
} survey

\author{
Juliet Ocwia' ${ }^{1}$, Ronald Olum², Pamela Atim', Florence Laker ${ }^{1}$, Jerom Okot' ${ }^{1}$, Senai Goitom Sereke², \\ Joseph Baruch Baluku3 ${ }^{3}$ Sarah Kiguli² and Felix Bongomin ${ }^{1,2^{*}}$
}

\begin{abstract}
Background: Dental health is often neglected by the majority of the population and has contributed to the global burden of oral diseases. We assessed awareness, utilization and barriers to seeking oral health care among adults in Nebbi District, Uganda.
\end{abstract}

Methods: A community-based, cross sectional study was conducted in the central division, Nebbi District in Uganda among adults between the age of 18 years or older. An interviewer-administered, semi-structured questionnaire was used for data collection on socio-demographic characteristics, oral health awareness, oral health utilization, associated factors and barriers.

Results: A total of 400 adults with a median age of 32 years (interquartile range $24-43$ ) years were enrolled. More than half $(57.5 \%, n=230)$ of the participants were female. Participants identified smoking $(42.8 \%, n=171)$ and consumption of sugary foodstuffs $(29.0 \%, n=116)$ as risk factors for oral disease. Not brushing was also identified by 260 participants (65.0\%) as the cause of tooth decay and $95.8 \%(n=383)$ believed brushing one's teeth could prevent tooth decay. Of the $51.5 \%(n=206)$ who had experienced a toothache or discomfort 12 months prior to the study but only about half $(52 \%, n=106)$ had sought healthcare from a dental clinic or facility. About $89.5 \%(n=94)$ of the participants were able to see a dentist during their last visits. Dental carries $(76.6 \%, \mathrm{n}=70)$ and gum bleeding $(14.9 \%$, $n=14)$ were the most frequent reasons for visiting a dental clinic, and $73.7 \%(n=70)$ had their tooth extracted. Barriers to seeking oral healthcare were cost of treatment $(47.5 \%, n=190)$, and long waiting time $(18.5 \%, n=74)$. The odds of seeking oral healthcare was 2.8-fold higher in participants who were being married (Odds ratio (OR): $2.8,95 \% \mathrm{Cl}$ 1.3-6.3, $p=0.011$ ) and 3.5-fold higher among housewives (COR: 3.5, 95\% Cl 1.1-11.4, $p=0.040$ ).

Conclusion: About half of the participants had sought healthcare following a dental condition. Cost of treatment seems to be an important factor affecting utilization of oral health services. Optimization of costs, and creating awareness regarding benefits of utilizing preventive dental services are recommended.

Keywords: Oral health, Dental caries, Utilization, Associated factors, Knowledge, Nebbi, Uganda

*Correspondence: drbongomin@gmail.com

${ }^{1}$ Faculty of Medicine, Gulu University, Gulu, Uganda

Full list of author information is available at the end of the article

\section{Background}

Oral diseases represent a major public health challenge globally, and yet remain neglected. It is estimated that oral diseases affect over 3.5 billion people worldwide, with dental caries of permanent teeth being the most common condition $[1,2]$. Globally, it is estimated that 2.3 
billion people suffer from caries of permanent teeth and more than 530 million children suffer from caries of primary teeth [2].

The burden of oral diseases is more severe in poor and disadvantaged population groups. A systematic review has suggested a $20.8 \%$ increase in the global burden of oral conditions in the past decades, and this has been attributed to population growth and aging [2]. HIV/AIDS is also an important risk factor for oral diseases, especially in sub-Saharan Africa which has the highest burden of HIV [3].

In Uganda, there is inadequate data on the oral health. A community-based oral health survey reported that just over half of adults in communities in Uganda had at least one oral health concern 6 months prior to the survey. Of these, only about one-third received the appropriate treatment [4]. In this survey, tooth decay was found to be the most common oral health concern and several underlying risk factors such as oral hygiene, health seeking behaviors and health systems factors were identified [4].

Despite the high levels of oral diseases in Uganda [5], utilization of oral health services is still very low as people visit dental clinics for pain relief or in need of emergency services [6]. Utilization of oral health services and its barriers become important parameters in oral health planning [6]. This is because they provide useful information and guidance to health planners and policy makers to help in developing appropriate structures and appropriate resource allocation [6].

The purpose of this study was to assess the awareness, utilization and barriers to seeking oral health among adults in Nebbi District, Uganda.

\section{Methods}

\section{Study design}

This was a community-based, cross sectional study with a quantitative approach. The study was conducted between October and December 2020.

\section{Study setting}

The study was conducted in Nebbi district, a rural district in Uganda, located in West-Nile sub-region, Northern Uganda. Nebbi has a municipal council which has three divisions namely Central, Thatha and Abindu division. This study was conducted in the central division. Nebbi District has a population of 282,600 (Male: 49\%; Female: 51\%), 145,400 female, 137,200 males (UBOS Population projection 2020). Nebbi district has two public health center (HC) level four (HC IV) and two general hospitals which provide dental health services [7]. In Uganda, an HC IV offers a comprehensive medical, surgical and maternity services including dentistry. The unit is headed by a medical doctor. Dental services at HCIV is offered by a dental public health practitioners and nurses trained in dental health care.

\section{Study population}

The target population comprised of community members living in the rural areas of Central Division, Nebbi District, Uganda.

\section{Sampling method}

We used simple random sampling to select households. Everyone in the selected household was eligible for the study as long as he or she was within the age limits and was willing to provide informed consent.

\section{Sample size calculation}

The sample size was calculated using Kish-Leslie formula (1965) as summarized below:

$$
\mathrm{N}=\frac{Z^{2} p(1-p)}{d^{2}}
$$

where $\mathrm{N}=$ Sample size required. $\mathrm{Z}=$ standard normal distribution abscissa corresponding to $95 \%$ confidence interval (1.96). $\mathrm{P}=$ Proportion of persons underutilizing oral health services. An estimated value of $50 \%$ was used (0.5) since the proportion of persons underutilizing oral health care is not known. $\mathrm{D}=$ Desired level of precision/ marginal error (0.05)

$$
\mathrm{N}=\frac{Z^{2} p(1-p)}{d^{2}}
$$

$\mathrm{N}=\left(1.96^{2} \times 0.5(1-0.5)\right) / 0.05^{2} . \mathrm{N}=384$. Non-response of $10 \%$ was 38 people. Hence the sample size was 422 .

\section{Selection criteria}

We included all adults aged 18 to 65 years old who consented to participate were included in the study. Persons who were too sick and mentally ill to participate were not included in the study.

\section{Data collection}

A semi-structured questionnaire (Additional file 1) was used to collect quantitative data on: demographics (age, sex, address, religion, occupation, and marital status), source of income, estimated monthly income, household population, and distance to nearest health facility, awareness on oral health, oral health seeking among individuals with an oral complaint and barriers to seeking oral health services. The questionnaire was pre-tested in another division to ensure its reliability and validity in assessing the study variables. Cronbach alpha score was 0.80 for all questions showing a very high internal validity. During the study, the questionnaires was assessed for 
completeness and kept safely awaiting data analysis. We collected data using an interviewer -administered semi structured questionnaire. All interviewers were trained nurses who underwent a two-day training on the study and the data collection tool. All interviewers participated in the pilot study and pre-testing of the study tool.

\section{Data analysis}

Data was analyzed using STATA version 16.0 Categorical data was summarized into frequencies and percentages and numerical data as means and standard deviations or medians and interquartile ranges (IQR) as appropriate. Chi-square tests were performed to look for association between categorical independent variables and the dependent variables and student $\mathrm{t}$-test or Mann-Whitney $\mathrm{U}$ tests were used to assess for association between numerical independent variables and the dependent. Multivariable logistic regression was performed for all variables with a $p<0.2$ at bivariate analysis to assess for factors associated with seeking of dental services. A $p<0.05$ was considered statistically significant.

\section{Ethical considerations}

The research proposal was approved by the Gulu University Research \& Ethics committee. All participants provided informed written consents. All methods were performed in accordance with the Declaration of Helsinki.

\section{Results}

\section{Socio-demographic data of the participants}

Of the anticipated 422 participants, a total of 400 adults (response rate 95\%), with a median age of 32 years (IQR: 24 to 43 years) participated in the study. More than half were female $(57.5 \%, \mathrm{n}=230)$, aged 18 to 35 years $(58.5 \%$, $\mathrm{n}=234)$ and had attained primary education $(56.0 \%$, $\mathrm{n}=224)$. About two-thirds were married (68.5\%) and were farm laborers $(62.2 \%)$. The main source of income was farming (45\%), with an estimated median monthly income of 50,000 UGX (IQR: 20,000 UGX to 100,000 UGX; 13.5 US dollars (USD), IQR-5.5 USD to 27 USD). Table 1 summarizes the social and demographic characteristics of the participants.

\section{Knowledge and practices towards oral hygiene}

Table 2 summarizes the knowledge and practices of adults towards oral hygiene. The most frequently identified risk factors for oral disease were smoking (42.8\%, $\mathrm{n}=171)$ and consumption of sugary foodstuffs $(29.0 \%$, $\mathrm{n}=116)$. Some $23.3 \%(\mathrm{n}=93)$ did not know any risk factors. Not brushing was also identified by 260 participants $(65.0 \%)$ as the cause of tooth decay and the greatest majority believed brushing one's teeth could prevent
Table 1 Characteristics of participants

\begin{tabular}{|c|c|c|}
\hline Variable & $\begin{array}{l}\text { Frequency } \\
(N=400)\end{array}$ & Percent (\%) \\
\hline Age in years (median, IQR) & 32 & $24-43$ \\
\hline $18-35$ years & 234 & 58.5 \\
\hline $36-60$ years & 143 & 35.8 \\
\hline$>60$ years & 23 & 5.8 \\
\hline \multicolumn{3}{|l|}{ Education level } \\
\hline No formal education & 62 & 15.5 \\
\hline Primary & 224 & 56.0 \\
\hline Secondary & 90 & 22.5 \\
\hline Tertiary/university & 24 & 6.0 \\
\hline \multicolumn{3}{|l|}{ Occupation $(n=397)$} \\
\hline Farm labourers & 247 & 62.2 \\
\hline Business & 95 & 23.9 \\
\hline Housewife & 34 & 8.6 \\
\hline Civil servant & 21 & 5.3 \\
\hline \multicolumn{3}{|l|}{ Marital status } \\
\hline Married & 274 & 68.5 \\
\hline Single & 76 & 19.0 \\
\hline Divorced/separated & 37 & 9.3 \\
\hline Widow/widower & 13 & 3.3 \\
\hline \multicolumn{3}{|l|}{ Source of income } \\
\hline Farming & 179 & 45.0 \\
\hline Business & 148 & 37.2 \\
\hline Support from friends or family & 52 & 13.1 \\
\hline Formal employment & 19 & 4.8 \\
\hline $\begin{array}{l}\text { Number of people in homestead } \\
(n=386) \text {, median, range }\end{array}$ & 6 & $4-8$ \\
\hline
\end{tabular}

tooth decay $(95.8 \%, \mathrm{n}=383)$. Some 79 adults $(19.8 \%)$ used sticks for brushing and 6 participants each using either soap or sand. $56.5 \%(n=226)$ reported brushing their teeth at least twice a day.

\section{Utilization of oral health services}

Up to $51.5 \%(\mathrm{n}=206)$ had experienced a toothache or discomfort 12 months prior to the study (Table 3 ). Of these, only about half $(52 \%, n=106)$ had sought healthcare from a dental clinic or facility. The major reason for seeking care was toothache $(86.7 \%, \mathrm{n}=91)$. Eighty-nine percent $(n=94)$ were able to see a dentist during their last visits. Dental caries (76.6\%) and gum bleeding (14.9\%) were the most frequent treated conditions, and the majority were treated by tooth extraction $(73.7 \%, \mathrm{n}=70)$. Most participants reported that the dentist was friendly during their care and treatment $(80.2 \%, \mathrm{n}=77)$. Marital status was significantly associated with utilization of oral health services $(p=0.013)$. The odds of seeking oral health services was 3.5 -fold higher among housewives (COR: 3.5, 95\% CI 1.1-11.4, 
Table 2 Knowledge and practices towards oral hygiene among adults

\begin{tabular}{|c|c|c|}
\hline Question & $\begin{array}{l}\text { Frequency } \\
(\mathrm{N}=400)\end{array}$ & Percent (\%) \\
\hline \multicolumn{3}{|l|}{ Risk factors for oral disease } \\
\hline Smoking & 171 & 42.8 \\
\hline Consumption of sugary foodstuffs & 116 & 29.0 \\
\hline I don't know & 93 & 23.3 \\
\hline Alcohol consumption & 17 & 4.3 \\
\hline Sweet drinks at bedtime & 3 & 0.8 \\
\hline \multicolumn{3}{|l|}{ Cause of tooth decay } \\
\hline Not brushing & 260 & 65.0 \\
\hline I don't know & 69 & 17.3 \\
\hline Consumption of sugary foodstuffs & 61 & 15.3 \\
\hline Hereditary & 10 & 2.5 \\
\hline \multicolumn{3}{|l|}{ How to keep your teeth clean } \\
\hline Brushing the teeth & 383 & 95.8 \\
\hline I don't know & 10 & 2.5 \\
\hline Avoid eating sweet foodstuffs & 4 & 1.0 \\
\hline Avoid sweet drinks at bedtime & 2 & 0.5 \\
\hline Avoid smoking & 1 & 0.3 \\
\hline \multicolumn{3}{|c|}{ What do you use for cleaning your teeth? } \\
\hline Toothbrush & 315 & 78.8 \\
\hline Sticks & 79 & 19.8 \\
\hline Sand & 3 & 0.8 \\
\hline Soap & 3 & 0.8 \\
\hline \multicolumn{3}{|l|}{ How often do you brush in a day? } \\
\hline Once & 174 & 43.5 \\
\hline Twice & 156 & 39.0 \\
\hline Thrice & 70 & 17.5 \\
\hline \multicolumn{3}{|l|}{$\begin{array}{l}\text { Duration taken while brushing the teeth } \\
(n=398)\end{array}$} \\
\hline I don't know & 264 & 66.3 \\
\hline $2 \mathrm{~min}$ & 69 & 17.3 \\
\hline $1 \mathrm{~min}$ & 49 & 12.3 \\
\hline $20 \mathrm{~s}$ & 16 & 4.0 \\
\hline
\end{tabular}

$p=0.040)$ and 2.8-fold higher among married participants (COR: 2.8, 95\% CI 1.3-6.3, $p=0.011$ ). However, multivariable logistic regression did not reveal statistically significance.

\section{Barriers to seeking healthcare for dental conditions}

Financial problems, lack of time and non-severe dental diseases were the most common reasons (Fig. 1). The five most frequent reasons for barriers to seeking dental healthcare were, (I) cost of treatment $(47.5 \%, \mathrm{n}=190)$, (II) long waiting time $(18.5 \%, \mathrm{n}=74)$, (III) distance to the facility $(9.8 \%, \mathrm{n}=39)$, (IV) fear of pain $(8.5 \%$, $\mathrm{n}=34)$ and $(\mathrm{V})$ attitudes of the dentists $(3.8 \%, \mathrm{n}=15)$.
Table 3 Utilization of oral health services among adults

\begin{tabular}{|c|c|c|}
\hline Variable & Frequency & $\%$ \\
\hline \multicolumn{3}{|c|}{$\begin{array}{l}\text { Toothache or oral discomfort in the past } 12 \text { months } \\
(n=400)\end{array}$} \\
\hline Yes & 206 & 51.5 \\
\hline No & 194 & 48.5 \\
\hline \multicolumn{3}{|c|}{$\begin{array}{l}\text { Level of utilization of oral health services following an } \\
\text { oral condition in the past } 12 \text { months }(n=204)\end{array}$} \\
\hline No & 98 & 48.0 \\
\hline Yes & 106 & 52.0 \\
\hline \multicolumn{3}{|c|}{$\begin{array}{l}\text { The main reason for your last visit to dental clinic } \\
(n=105)\end{array}$} \\
\hline Painful tooth & 91 & 86.7 \\
\hline Regular check-up & 10 & 9.5 \\
\hline Follow-up & 2 & 1.9 \\
\hline Sensitivity of the teeth & 2 & 1.9 \\
\hline \multicolumn{3}{|c|}{ Were you able to see the dentist? $(n=105)$} \\
\hline No & 11 & 10.5 \\
\hline Yes & 94 & 89.5 \\
\hline \multicolumn{3}{|c|}{ What conditions were you treated for? $(n=94)$} \\
\hline Caries & 72 & 76.6 \\
\hline Bleeding gum & 14 & 14.9 \\
\hline Dental abscess & 3 & 3.2 \\
\hline Fractured tooth & 3 & 3.2 \\
\hline Sensitivity of the teeth & 2 & 2.1 \\
\hline \multicolumn{3}{|c|}{ Types of treatment received } \\
\hline Tooth extraction & 70 & 73.7 \\
\hline Medication & 18 & 18.9 \\
\hline Cleaning & 4 & 4.2 \\
\hline Filling & 2 & 2.1 \\
\hline Oral education & 1 & 1.1 \\
\hline \multicolumn{3}{|c|}{ Means to reach the health facility for oral care? $(n=96)$} \\
\hline Walking & 72 & 75.0 \\
\hline Boda-Boda* & 23 & 24.0 \\
\hline Public means(vehicle) & 1 & 1.0 \\
\hline \multicolumn{3}{|c|}{ How long did it take you to receive help? $(n=96)$} \\
\hline $3 \mathrm{~h}$ & 34 & 35.4 \\
\hline $1 \mathrm{~h}$ & 22 & 22.9 \\
\hline $2 \mathrm{~h}$ & 22 & 22.9 \\
\hline $30 \mathrm{~min}$ & 18 & 18.8 \\
\hline \multicolumn{3}{|c|}{ What was the dentist's response towards you? $(n=96)$} \\
\hline Friendly & 77 & 80.2 \\
\hline Busy & 10 & 10.4 \\
\hline Rude & 9 & 9.4 \\
\hline
\end{tabular}

*Boda-Boda is a form of bicycle and motorcycle taxis commonly used in Uganda. Transport fares are charged according to the distance covered

\section{Discussion}

This study sought out to determine the practices, utilization, and barriers to oral health services in a rural district in Northwestern Uganda. The results of our study show that half of the participants had experienced a toothache 


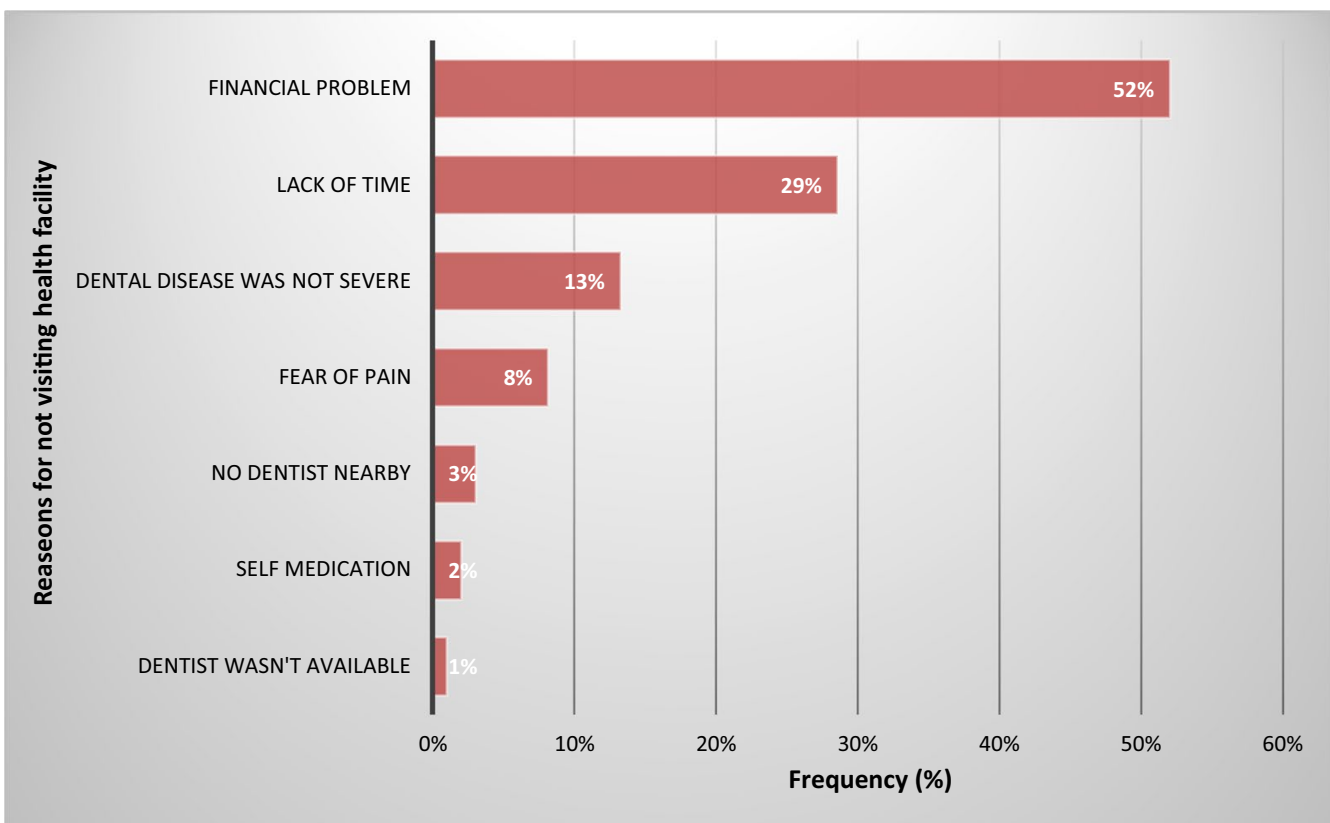

Fig. 1 Reasons for not visiting the health facility during the last episode of tooth discomfort $(n=98)$

or discomfort 12 months prior to the study. However, only about half of these had sought healthcare from a dental clinic or facility. The most reported reason for not seeking dental care is the widely held perception that one needs to visit dentist only when there are symptoms such as pain and emergency. Many studies show that one key reason for this is the belief that oral diseases are not serious or life threatening. Studies done in India show that about between $62.5 \%$ and $70 \%$ of the participants believed that unless there is pain, there is no need to visit a dentist $[8,9]$.

The major reason for seeking oral healthcare was toothache. This is supported by study done in India where reported reasons for visiting dentist in the past were related to having oral symptoms or pain $[10,11]$. In other studies, done in Tanzania, dental pain and discomfort were cited as common reasons for seeking dental care $[12,13]$. Kadarulu and colleagues also found in their study that the majority of the dental visits were for pain relief [14]. Visiting the dentist for regular check-up as a preventive measure of common oral diseases, was not well known. In this study, only $9.5 \%$ of the participants mentioned it as a measure of oral disease prevention meaning early identification and prevention of oral diseases are always made difficult since most people came at later stages of the disease leaving them with no other options of treatment other than tooth extraction, which is similar to a study conducted in India where the people interviewed said they had never visited a dentist for routine oral examination [15].

The results of this study showed that most participants had good knowledge about the risk factors for oral disease. Majority of them identified smoking (42.8\%) and consumption of sugary foodstuffs $(29.0 \%)$ were risk factors for oral disease. Some $23.3 \%$ did not know any risk factors. Risk factors for oral diseases include unhealthy eating habits or diet, tobacco use, harmful alcohol use, and poor oral hygiene [16]. In our study, knowledge on prevention of oral diseases varied as the greatest majority of the participants knew that brushing teeth thoroughly prevents cavities, but only a small percentage knew that one form of prevention of dental caries is to avoid eating sugary foods. The international studies have showed that patients with generally higher levels of education than our study participants (for example university students in Ethiopia and teachers and students in India) had greater knowledge of preventive measure of gum diseases and caries $[17,18]$. Education level was however not significant in our study.

In this study, $9.8 \%$ of the participants expressed that distance to the facility hinders them from accessing oral health service because they have to walk long distances in order seek of oral care. Similar studies also show that people in rural areas often have greater distances to travel to reach health care services where the availability of transport is limited and costs higher $[19,20]$. 
There are noted differences between urban and rural areas and proximity to oral health services.

Our study has important limitations. The sample size is small and mainly rural. Therefore, our study may not be generalized to the entire Ugandan population. However, we provide an important baseline epidemiological study to inform future public health surveillance and interventions.

\section{Conclusion}

In conclusion, whereas most of the participants had good awareness on oral health, only about half of them sought oral health services for an oral health condition in the past twelve months. Cost of treatment, long waiting time and distance to the health facility were frequently reported barriers.

\section{Supplementary Information}

The online version contains supplementary material available at https://doi. org/10.1186/s12903-021-01824-5.

Additional file 1. A semi-structured questionnaire.

\section{Acknowledgements}

Research reported in this publication was supported by the Fogarty International Center of the National Institutes of Health, U.S. Department of State's Office of the U.S. Global AIDS Coordinator and Health Diplomacy (S/GAC), and President's Emergency Plan for AIDS Relief (PEPFAR) under Award Number 1R25TW011213. The content is solely the responsibility of the authors and does not necessarily represent the official views of the National Institutes of Health.

\section{Authors' contributions}

Conceptualization: JO (first author), FB. Study design: JO (first author), FB, PA. Execution: JO (first author), RO, PA, LF, JO, SGS, JBB, SK, FB. Acquisition of data: JO. Analysis and interpretation: RO, PA, JBB, JO, FB. Original draft: JO (first author), FB, PA. Execution: JO (first author), RO, PA, LF, JO, SGS, JBB, SK, FB. All authors read and approved the final manuscript.

\section{Funding}

None.

\section{Availability of data and materials}

The datasets used and/or analyzed during the current study are available from the corresponding author on reasonable request.

\section{Declarations}

\section{Ethics approval and consent to participate}

All participants provided informed written consent after the study procedure; risks and benefits were explained to them. Gulu University Research and Ethics Committee approved the study protocol.

\section{Consent for publication}

Not applicable.

\section{Competing interests}

The authors declare no competing interests.

\section{Author details}

${ }^{1}$ Faculty of Medicine, Gulu University, Gulu, Uganda. ${ }^{2}$ School of Medicine, College of Health Science, Makerere University, Kampala, Uganda. ${ }^{3}$ Kiruddu National Referral Hospital, Kampala, Uganda.

Received: 9 April 2021 Accepted: 13 September 2021

Published online: 17 September 2021

\section{References}

1. Naghavi M, Abajobir AA, Abbafati C, Abbas KM, Abd-Allah F, Abera SF, et al. Global, regional, and national age-sex specific mortality for 264 causes of death, 1980-2016: a systematic analysis for the Global Burden of Disease Study 2016. Lancet. 2017;390:1151-210. https://doi. org/10.1016/S0140-6736(17)32152-9.

2. Marcenes W, Kassebaum NJ, Bernabé E, Flaxman A, Naghavi M, Lopez A, et al. Global burden of oral conditions in 1990-2010. J Dent Res. 2013;92:592-7. https://doi.org/10.1177/0022034513490168.

3. Chapple ILC. The significance of oral health in HIV disease. Sex Transm Infect. 2000;76:236-43. https://doi.org/10.1136/sti.76.4.236.

4. Ministry of Health Uganda. National Oral Healh Survey. 2007.

5. Kutesa A, Kasangaki A, Nkamba M, Muwazi L, Okullo I, Rwenyonyi CM. Prevalence and factors associated with dental caries among children and adults in selected districts in Uganda. Afr Health Sci. 2016;15:1302. https://doi.org/10.4314/ahs.v15i4.33.

6. Jain VK, Sequeira P, Jain J, Chancy U, Maliyil MJ, Bhagwandas SC. Barriers in utilization of oral health care services among patients attending primary and community health centres in Virajpet, South Karnataka. Natl J Med Dent Res. 2013;1:39.

7. Ministry of Health Uganda. National Health Facility Master List. 2017.

8. Fotedar S, Sharma K, Bhardwaj V, Sogi G. Barriers to the utilization of dental services in Shimla. India Eur J Gen Dent. 2013;2:139. https://doi. org/10.4103/2278-9626.112314.

9. Aikins $E$, Braimoh $O$. Utilization of dental services among civil servants in Port Harcourt. Nigeria J Dent Res Rev. 2015;2:62. https://doi.org/10. 4103/2348-2915.161202.

10. Kakatkar G, Bhat N, Nagarajappa R, Prasad V, Sharda A, Asawa K, et al. Barriers to the utilization of dental services in Udaipur, India. J Dent (Tehran). 2011:8:81-9.

11. Ajayi D, Arigbede A. Barriers to oral health care utilization in Ibadan, South West Nigeria. Afr Health Sci. 2013;12:25. https://doi.org/10.4314/ ahs.v12i4.17.

12. Kikwilu EN, Masalu JR, Kahabuka FK, Senkoro AR. Prevalence of oral pain and barriers to use of emergency oral care facilities among adult Tanzanians. BMC Oral Health. 2008:8:28. https://doi.org/10.1186/ 1472-6831-8-28.

13. Mashoto KO, Åstrøm AN, David J, Masalu JR. Dental pain, oral impacts and perceived need for dental treatment in Tanzanian school students: a cross-sectional study. Health Qual Life Outcomes. 2009;7:73. https:// doi.org/10.1186/1477-7525-7-73.

14. Kadaluru U, Kempraj $\mathrm{V}$, Muddaiah P. Utilization of oral health care services among adults attending community outreach programs. Indian J Dent Res. 2012;23:841. https://doi.org/10.4103/0970-9290.111290.

15. Devaraj C, Eswar P. Reasons for use and non-use of dental services among people visiting a dental college hospital in India: a descriptive cross-sectional study. Eur J Dent. 2012:6:422-7.

16. World Health Organisation. Oral health. Fact sheets. 2020. https://www. who.int/news-room/fact-sheets/detail/oral-health. Accessed 7 Mar 2021.

17. Darout I. Knowledge and behavior related to oral health among Jimma University Health Sciences students, Jimma, Ethiopia. Eur J Gen Dent 2014;3:185. https://doi.org/10.4103/2278-9626.141663.

18. Bennadi D, Gaduputi S, Konda Reddy C, Kshetrimayum N, Reddy V, Siluvai S. Oral health related knowledge, attitude, and practice among the pre-university students of Mysore city. J Int Soc Prev Community Dent. 2014;4:154. https://doi.org/10.4103/2231-0762.142012.

19. Noor AM, Zurovac D, Hay SI, Ochola SA, Snow RW. Defining equity in physical access to clinical services using geographical information systems as part of malaria planning and monitoring in Kenya. Trop 
Med Int Heal. 2003;8:917-26. https://doi.org/10.1046/j.1365-3156.2003. 01112.x.

20. Buor D. Analysing the primacy of distance in the utilization of health services in the Ahafo-Ano South district, Ghana. Int J Health Plann Manag. 2003;18:293-311. https://doi.org/10.1002/hpm.729.

\section{Publisher's Note}

Springer Nature remains neutral with regard to jurisdictional claims in published maps and institutional affiliations.
Ready to submit your research? Choose BMC and benefit from:

- fast, convenient online submission

- thorough peer review by experienced researchers in your field

- rapid publication on acceptance

- support for research data, including large and complex data types

- gold Open Access which fosters wider collaboration and increased citations

- maximum visibility for your research: over $100 \mathrm{M}$ website views per year

At BMC, research is always in progress.

Learn more biomedcentral.com/submissions 